\title{
DESCRIPTION OF \\ HASTE'S IMPROVED SAFETY VALVE FOR STEAM BOILERS.
}

BY Mr. WILLIAM NAYLOR, OF LONDON.

In the explosions of steam boilers, which are still of frequent occurrence, the cause of the explosion too often remains a mystery, and is not satisfactorily ascertained so as to afford a guide towards guarding against the recurrence of such accidents. The author has a strong impression that in several cases of boiler explosions the cause has been simply over-pressure beyond the calculated or known pressure in the boiler; and that the over-pressure was caused by the safety valve in use not carrying away the steam as fast as it was generated. In three cases that came under his particular observation, the firing was going on as if the engines were in full work; whereas neither were the engines at work, nor was any feed water being pumped into the boiler for some 10 or 15 minutes before the explosions took place: consequently the boilers were generating as much steam as would have supplied the engines at work; and in addition the amount of fuel required for heating the feed water from the temperature at which it entered was spent also in generating steam, so that more steam had to pass away through the safety valve than was necessary to work the engines at their full power.

A safety valve loaded to a certain pressure per square inch, so that whenever that pressure is attained in the boiler the least addition to it will canse the steam to begin to escape, is not by any means a guarantee that the steam will be carried away as fast as it is generated, and no surplus pressure allowed to accumulate in the boiler above that at which the valve is loaded to blow off; and it appears from experience that ordinary safety valves do not effect this object, as further shown by experiments afterwards described. At the time when 50 lbs. per square inch was the working pressure in locomotive engines, say 25 years ago, 
the practice was to have one valve loaded by a lever and spring balance to 50 lbs. per square inch, and a second valve similarly loaded up to $60 \mathrm{lbs}$. per square inch. The author has frequently noticed that when the one at $50 \mathrm{lbs}$. was blowing off strongly the one at $60 \mathrm{lbs}$. would begin to blow off, and often both valves would blow off very strongly; proving that there must be a surplus pressure of at least $10 \mathrm{lbs}$. per square inch above that at which one valve was intended to carry the steam away as fast as it was generated. Such ralves loaded by levers and spring balances are very generally used on boilers supplying moderately high pressure steam to stationary engines, and also on locomotive engines; but they are defective under the most favourable circumstances, if required to pass any great amount of steam; and they are open to the objection that they may be overloaded by weights being added on the lever. In this respect there are a few valuable exceptions, but only a very few, in use at the present time.

The want of a sufficient amount of water in the boiler is also no doubt the chief cause of many explosions of steam engine boilers, more especially those attached to stationary engines. For by the water getting below the top of any portion of the heating surface which is acted upon by the fire, that portion soon becomes overheated and reduced in strength, until it is unable to bear the pressure of the steam upon it; under these circumstances something must give way, and the result must be an explosion.

It is therefore desirable that an arrangement of safety valve should be adopted which will accomplish the three following objects : to carry off the steam as fast as it is generated above the pressure the boiler is intended to work at; to be entirely out of the reach or control of any one to tamper with or overload it; and to be so arranged that, in the event of the water getting low in the boiler, the valve shall blow off steam and avoid the possibility of any explosion or injury beyond the burning of the plates if more water be not supplied.

The plan of safety valve forming the subject of the present paper, which is the invention of Mr. J. Haste of Leeds, has proved highly successful in accomplishing these objects. The arrangement is represented in Fig. 1, Plate 38, showing a section of the valve and 
its connexion with the boiler; Fig. 2 shows a section of the valve enlarged.

The valve $A$, by which the steam escapes into the atmosphere when the limit of pressure is exceeded, is made with two seats, the upper one being 3 inches diameter and the lower $3 \frac{1}{4}$ inches diameter, the difference being 1.23 square inch area. The steam presses on both ends of the valve, passing up through the middle of it, so that when the valve is open the steam escapes at both ends into the casing surrounding the valve and thence into the atmosphere. This valve is not moved off its seats by the steam acting upon the difference of area of the two ends, but is forced open by steam acting upon the piston $B$, the rod of which presses upon the valve $A$. The small safety valve $C$, by which the limit of pressure of the steam is fixed, is loaded by a dead weight $D$ enclosed in a chamber and guided at the top by a small piston $\mathrm{E}$ working in a cylinder of the same area as the valve $\mathrm{C}$ below. Whenever the pressure of steam in the boiler exceeds that to which the small valve $C$ is loaded, it will be raised from its seat; and the steam escaping will accumulate in pressure upon the top of the piston B. The area of this piston is 7 square inches, or mearly 6 times the difference of area of the valve seats A. Taking the pressure of steam in the boiler at $35 \mathrm{lbs}$. per square inch, there is a force of $42 \mathrm{lbs}$. tending to keep the escape valve $A$ closed, equivalent to a pressure of $6 \mathrm{lbs}$. per square inch on the under side of the piston B; so that when the pressure above the piston has reached 6 lbs. per square inch, any increase of pressure must open the escape valve $A$ : and if there be a pressure of $35 \mathrm{lbs}$. per square inch upon the piston $\mathrm{B}$, this gives a force of $245 \mathrm{lbs}$. tending to open the escape valve against a resistance of $42 \mathrm{lbs}$., leaving an effective force of more than $200 \mathrm{lbs}$. to open the escape valve A. Upon the area of opening afforded by the valve will depend the efficiency of its action in preventing a surplus pressure of steam from accumulating in the boiler.

One of these safety valves, of the construction shown in Plate 38, is attached to a boiler at the works of Messrs. Bray and Waddington of Leeds. The boiler is 24 feet 3 inches long and 6 feet 6 inches diameter, with two flues of 2 feet 6 inches diameter, and firebars 6 feet long in the flues, giving an area of firegrate of 30 square feet: it 
supplies steam to three non-condensing engines of 34 total horse power, working at $35 \mathrm{lbs}$. per square inch pressure. In order to ascertain by experiment the action of the valve, a pressure gange was attached to the top of the chamber $D$ in addition to one placed on the boiler : the small valve $\mathrm{C}$ was loaded to $35 \mathrm{lbs}$. per square inch. After many trials with the whole of the steam that the boiler could generate passing through the escape valve $A$, the pressure did not exceed $37 \mathrm{lbs}$. per square inch in the boiler or a surplus pressure of $2 \mathrm{lbs}$. per inch. The valve $A$ was then purposely prevented from blowing off until there was a surplus pressure of $3 \mathrm{lbs}$. per square inch upon the piston $\mathrm{B}$ as well as in the boiler, as shown by the two pressure gauges; the valve $A$ was then forced full open by the pressure of steam, and it was found that the pressure in the boiler was reduced to $35 \mathrm{lbs}$. per square inch in a few minutes.

In order to ascertain the real value of this safety valve as compared with the ordinary valve, the following experiments have been tried by the writer, in which every care was taken to prevent error in the result : the fires were clean and free from clinker, the fuel good coal and well ignited; none of the engines were at work, nor was there any outlet for steam to escape except those intentionally allowed; nor was any feed water pumped into the boiler during the time of experiment.

The first object in the trials was to ascertain how fast the pressure of steam conld be raised to the point of blowing off; say from $5 \mathrm{lbs}$. up to $35 \mathrm{lbs}$. per square inch. This time was found to be 13 minutes, making $2 \cdot 3 \mathrm{lbs}$. rise of pressure per minute.

The next object was to see how the pressure would be affected by an opening of 1 square inch area being allowed for the steam to escape through; and when the pressure had been raised to $35 \mathrm{lbs}$. per square inch, a slide valve was opened turning the steam into a 4 inch branch pipe, upon which was bolted a plate with a hole of 1 square inch area, through which the steam escaped freely into the atmosphere. It was then found that the pressure in the boiler oscillated between $35 \mathrm{lbs}$. and $43 \mathrm{lbs}$. per square inch; and at the end of 45 minutes the maximum of 43 lbs. pressure was attained. The slide valve was then 
shut and the steam turned on so as to pass out by the new safety valve, shown in Fig. 1, Plate 38 ; the pressure gauge on the boiler and that on the chamber $\mathrm{D}$ both showed $43 \mathrm{lbs}$. per inch, and the escape valve A was instantly forced full open and down upon the studs below it. The pressure in the boiler was then reduced by the valve from $43 \mathrm{lbs}$. to $38 \mathrm{lbs}$. in the first 5 minutes, and finally to the ordinary working pressure of $35 \mathrm{lbs}$. in 15 minutes. The firing for the whole hour had been much forced, and was much above that necessary to drive the engines in their ordinary work. On observing the water lerel it was found that in the hour $57 \cdot 5$ cubic feet of water had been evaporated into steam, which would be sufficient to have supplied a 60 horse power engine. Hence with this generation of steam a hole of 1 square inch area was sufficient to keep the pressure down to $43 \mathrm{lbs}$. per square inch during 45 minutes; while with the new safety valve the pressure was reduced to $35 \mathrm{lbs}$. in 15 minutes.

An experiment was then tried to ascertain how far an ordinary safety valve of $3 \frac{3}{4}$ inches diameter would keep the pressure from accumulating in the boiler above that at which it was set to blow off. The valve was loaded by a lever and spring balance, as shown in Fig. 3 , Plate 38 ; and $1 \mathrm{lb}$. on the balance was equal to $1 \mathrm{lb}$. per square inch on the valve. When the pressure gauge upon the boiler showed $43 \mathrm{lbs}$. per square inch and the spring balance was set at $43 \mathrm{lbs}$, there was a very slight blowing off at the valve, showing that the pressure gauge and spring balance agreed. The spring balance was then slacked back to $30 \mathrm{lbs}$, allowing the steam to blow off freely; in 5 minutes the pressure gange on the boiler showed 46 lbs., in another 5 minutes $46 \frac{1}{2} \mathrm{lbs}$, and in 5 minutes more $46 \mathrm{lbs}$. Thus for 15 minutes, with a valve loaded to only $30 \mathrm{lbs}$. per square inch above the atmosphere, the actual pressure in the boiler was $46 \mathrm{lbs}$, being a surplus of $16 \mathrm{lbs}$. above the pressure that the valve was adjusted to blow off at, or 35 per cent. of surplus pressure. In the previous experiment it has been seen that an opening of 1 square inch area carried off the steam as fast as it was generated, without allowing the pressure to exceed 43 lbs. per square inch. But in the present case, with a valve of $3 \frac{3}{4}$ inches diameter or 11 square inehes area, in order to give an opening of 1 square inch area round the circumference, $\cdot 085$ inch width of opening would 
be required, or 122 inch vertical lift of the valve, the circumference being 11.78 inches, and the face of the valve being inclined at an angle of $45^{\circ}$. This lift of the valve would extend the spring balance 1.34 inch, the leverage being $3 \frac{1}{4}$ and $35 \frac{3}{4}$ inches; and as the scale of the spring balance gave $12 \mathrm{lbs}$. for each inch of extension, an excess of pressure of $16 \mathrm{lbs}$. per square inch would be caused by this lifting of the valve in blowing off, which would give an area of opening of only 1 square inch for the steam to escape. This result agrees with the observed surplus pressure of $16 \mathrm{lbs}$. per square inch. In the ordinary safety valves there is also frequently a cause of over-pressure, in consequence of the valve being enclosed in a chamber, from which the steam escapes through a pipe into the atmosphere: if the steam is roaring through this pipe there must be some pressure of steam in the chamber to occasion that roar, thus causing an increased pressure on the valve above the limit to which it is intended to be loaded.

The other source of explosion,- - the want of water in the boiler,is provided against in this safety valve by the float $\mathbf{F}$, which on falling below its proper level opens the escape valve $\mathbf{A}$, and lets the steam escape from the boiler to the atmosphere regardless of its pressure. The author has found by repeated trial and the results of regular working that, whenever the water gets below the working level in the boiler, the float descending with it opens the escape valve, allowing the full opening for the discharge of the steam, and the valve cannot be closed again by any other means than the proper supply of water, raising the float to its original level. In experimenting upon the boiler, when the escape valve was opened by the float to the full extent, the pressure of steam was reduced at the rate of 2 lbs. per square inch per minute. The loud noise of the steam escaping could not fail of itself to call attention; but even if not attended to, the only result would be that the steam would be all let out of the boiler, and the engine stopped, all danger of accident being avoided. 
Mr. NAYLOn showed a sectional model of the valve and apparatus, and observed that the object was to ensure the pressure in the boiler never rising beyond the intended limit, by opening an escape for the steam when that limit was reached equal to the passage of the whole quantity that the boiler was capable of generating, and ensuring this passage being kept open until the pressure fell just below the fixed limit. The ordinary safety valves did not provide for this, and although there were some excellent constructions of valves to prevent overloading, such as Mr. Fenton's and Mr. Ramsbottom's safety valves, there was still no provision for preventing the pressure rising beyond the intended point when the boiler was generating steam rapidly, although the safety valve was in action; and a supplementary valve was required for this purpose, which would give a large area of discharge, by suddenly opening as soon as the limit of pressure was reached, effectually preventing any increase of pressure beyond that point. The same escape valve was also made to act in this apparatus to discharge the steam if the water in the boiler sank below the proper level; and it had this additional security against accident, that the continued escape of steam could be stopped only by the supply of water being again raised to the proper level: thus entirely preventing any risk of explosion, and acting as a strong inducement to the attendant to prevent a fall of the water level from occurring.

Mr. B. Fothergili observed that the principle of opening a supplementary escape valve, and causing it to be kept open so long as the pressure exceeded a fixed limit, was certainly an efficient one for ensuring the pressure being always limited to that point, which could not be effected by safety valves with spring balances; and if such an apparatus were simple and certain in its action, so that it could be fully depended upon, it would prove an important source of safety in steam boilers. He had seen a safety valve on that plan, contrived by Mr. Kay of Bury, that had been before a former meeting of the Institution, which he believed was working successfully.

The Chammas thought in any arrangement of the kind there still remained the objection of risk of the safety valve sticking; and in this plan the whole action depended upon the small safety valve keeping all right, which was liable to the same risk of derangement as 
ordinary safety valves, and in a greater degree on account of its small area compared with its length of circumference in contact with the seating. It appeared to him doubtful whether it was a safe course to pursue, to make the safety of the boiler dependent on the action of a single small valve, as was in effect the case in such an arrangement; and he thought it wonld be more correct to increase the area or number of the safety valves, if they were not found sufficient to keep down the pressure within safe limits. He enquired how long the apparatus shown had been at work.

Mr. NAYLOR replied that it had been working regularly for $1 \frac{1}{4}$ year, and had proved quite successful, and no imperfection had been found in its action. The action of the escape valve was certainly dependent upon the small safety valve, but he thought this was by its construction very free from risk of derangement and might be safely relied upon; and the pressure upon it could not be increased. The large area for discharge of steam given by the sudden opening of the escape valve was he thought a more efficient provision for preventing any increase of pressure than could be practically obtained with ordinary safety valves with spring balances.

Mr. H. MaUdsLax observed that in marine engine boilers it was usual to put two large safety valves, either of which would be sufficient to prevent any material increase in the boiler pressure, so as to afford a safe provision even in the case of one of the large valves failing to act from any cause. In safety valves he thought it was objectionable to have anything like a piston valve, on account of the liability to deposit collecting upon the rubbing surface and causing the valve to stick; and more particularly in the case of a locked up valve where it was liable to be left unopened for a long time, and a deposit might form, though very slowly, sufficient to impede the proper action of the valve. It was the essential point to be aimed at in any construction of safety valve to ensure certainty of action, as well as freedom from liability to derangement.

The Chairman moved a vote of thanks to Mr. Naylor for his paper, which was passed. 
The Meeting was then adjourned to the next day, and the Members proceeded to visit the Flax Mill of Messrs. Marshall \& Co., and several other engineering and manufacturing establishments that were thrown open for their inspection.

In the evening the Members and their friends were invited by the Local Committee to a Conversazione in the Victoria Hall of the Town Hall, where a number of engineering models, drawings, and photographs, philosophical instruments, and an extensive series of objects under microscopes, were exhibited.

The Adjourned Meeting of the Members was held in the Civil Court, Town Hall, Leeds, on Wednesday, 7th September, 1859, at half-past ten o'clock; John Penn, Esq., President, in the Chair.

The following Paper was read:- 


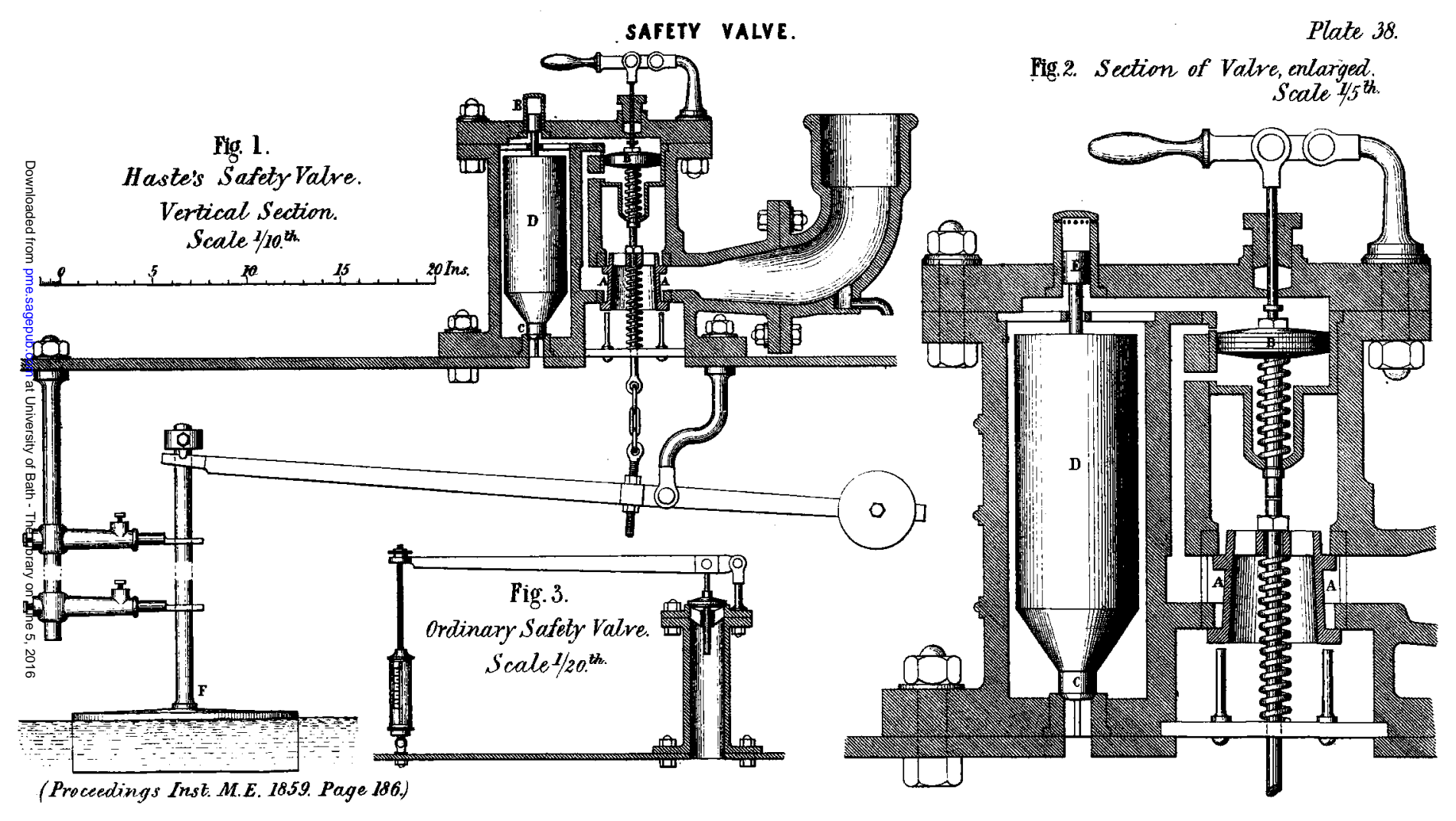

